\title{
ANFIS based prediction of the aluminum extraction from boehmite bauxite in the Bayer process
}

\author{
Ivan Mihajlović*, Isidora Đurić, Živan Živković \\ University of Belgrade, Technical Faculty in Bor, Serbia \\ Vojske Jugoslavije 12, 19210 Bor, Serbia \\ "Corresponding author: e-mail: imihajlovic@tf.bor.ac.rs
}

\begin{abstract}
This paper presents the results of nonlinear statistical modeling of the bauxite leaching process, as part of Bayer technology for alumina production. Based on the data, collected during the year 2011 from the industrial production in the alumina factory Birač, Zvornik (Bosnia and Herzegovina), nonlinear statistical modeling of the industrial process was performed. The model was developed as an attempt to define the dependence of the $\mathrm{Al}_{2} \mathrm{O}_{3}$ degree of recovery as a function of input parameters of the leaching process: content of $\mathrm{Al}_{2} \mathrm{O}_{3}, \mathrm{SiO}_{2}$ and $\mathrm{Fe}_{2} \mathrm{O}_{3}$ in the bauxite, as well as content of $\mathrm{Na}_{2} \mathrm{Ocaustic}$ and $\mathrm{Al}_{2} \mathrm{O}_{3}$ in the starting sodium aluminate solution. As the statistical modeling tool, Adaptive Network Based Fuzzy Inference System (ANFIS) was used. The model, defined by the ANFIS methodology, expressed a high fitting level and accordingly can be used for the efficient prediction of the $\mathrm{Al}_{2} \mathrm{O}_{3}$ degree of recovery, as a function of the process inputs under the industrial conditions.
\end{abstract}

Keywords: Leaching, bauxite, Bayer process, statistical modeling, ANFIS.

\section{INTRODUCTION}

In 1888, Karl Josef Bayer developed and patented a process which has become the cornerstone of the aluminum production industry worldwide ${ }^{1}$. The Bayer process of alumina extraction is a basic commercial procedure and more than $90 \%$ of the world alumina production is obtained in this way. Regardless of the fact that this process has been used for alumina production for a long period of time, there are still attempts for further improvements of the process ${ }^{2}$.

Bauxite is a complex heterogeneous ore material used in the Bayer process of alumina extraction. Aluminum is usually present in the bauxite in the form of hydroxide minerals, such as gibbsite (hydrargillite) $\left(\mathrm{Al}(\mathrm{OH})_{3}\right)$, boehmite $(\mathrm{AlO}(\mathrm{OH}))$ or diaspore $\left(\mathrm{HAlO}_{2}\right)$. Besides aluminum minerals, the bauxite ore contains various combinations of silica $\left(\mathrm{SiO}_{2}\right)$, aluminosilicates, iron oxide $\left(\mathrm{Fe}_{2} \mathrm{O}_{3}\right)$, titanium oxide $\left(\mathrm{TiO}_{2}\right)$ and other impurities; such as carbonates and sulfides, in trace amounts ${ }^{3-5}$. However, the most important constituents of the bauxite ore are $\mathrm{Al}_{2} \mathrm{O}_{3}, \mathrm{SiO}_{2}$ and $\mathrm{Fe}_{2} \mathrm{O}_{3}$, because their content directly determines its future behavior during the Bayer process.

Bayer process includes the high pressure leaching of bauxites in a concentrated sodium hydroxide (caustic) solution at temperatures, ranging from $373 \mathrm{~K}\left(100^{\circ} \mathrm{C}\right)$ to $523 \mathrm{~K}\left(250^{\circ} \mathrm{C}\right)$, depending on the mineralogical form of aluminum hydroxide in the bauxite $\mathrm{e}^{6-9}$. The process includes reactions with soluble silica compounds and titan dioxide under certain conditions ${ }^{\mathbf{1 0}}$. The rate of aluminum - hydroxide leaching process depends on its mineral form in the bauxite. The trihydrate bauxite type - gibbsite can be dissolved in a caustic solution in the temperature range of $373-453 \mathrm{~K}\left(100-180^{\circ} \mathrm{C}\right)$. Monohydrate bauxite forms (boehmite and diaspore) are dissolved in the following temperature ranges: 403-453 K $\left(130-180^{\circ} \mathrm{C}\right)$ and $473-523 \mathrm{~K}\left(200-250^{\circ} \mathrm{C}\right)$, respectively $1,11,12$.

The main source of aluminum and sodium hydroxide losses during the Bayer process is Sodium aluminosilicate which is precipitated in red mud. Sedimented red mud, obtained this way, also presents the environmental pro- blem, because it can be only partially recycled ${ }^{13}$. Most of its content is disposed at the waste yards. This problem attracts much attention nowadays, especially because of global environmental protection problems which demand the appliance of the global principles during local acting.

During the process of bauxite leaching in the alkaline sodium aluminate, the solution of aluminum ions are hydrolyzed in an aqueous environment forming numerous mononuclear and polynuclear hydroxo complex ions. Finally, in mild-to-strong alkaline solutions, the $\mathrm{Al}(\mathrm{OH})_{4}{ }^{-}$complex ion is the predominant one and, at $\mathrm{pH}$ higher than 10 , is the only existing aluminum - bearing ion in the solution ${ }^{13}$.

According to the available references, most important process parameters, influencing the degree of $\mathrm{Al}_{2} \mathrm{O}_{3}$ recovery during the leaching are: the mineralogical and chemical composition of bauxite, grain size distribution, $\mathrm{Al}_{2} \mathrm{O}_{3}$ concentration of the starting solution and its $\mathrm{Na}_{2} \mathrm{O}$ (caustic) content, leaching process temperature, stirring speed and duration of the process ${ }^{2,12-14}$.

Being influenced by large number of different input parameters, the process of bauxite leaching, under industrial conditions of Bayer technology for alumina production, is highly complex. The ability to predict the recovery of $\mathrm{Al}_{2} \mathrm{O}_{3}$ during the leaching, as the result of the input process parameters modeling, presents a great challenge for the management of the process ${ }^{\mathbf{1 0}}$.

Based on the facts described in previous sections, the main objective pursued in this work was to create a mathematical model for the prediction of the degree of $\mathrm{Al}_{2} \mathrm{O}_{3}$ recovery (output of the process), during boehmite bauxite leaching, as the function of the input parameters of the process. The obtained model presents a great advantage due to its ability to predict accurately enough the output of the investigated process, and as such is of great practical importance.

\section{EXPERIMENTAL DATA}

Data base, used for the calculations presented in this paper, was formed according to the data collected during the industrial production in the alumina factory Birač, 
Zvornik (Bosnia and Herzegovina). This factory has the production capacity of 600000 tons of alumina per year. The important process parameters included in the obtained database, were: the chemical composition of the bauxite (the main constituents including $\mathrm{Al}_{2} \mathrm{O}_{3}, \mathrm{SiO}_{2}$ and $\mathrm{Fe}_{2} \mathrm{O}_{3}$ ); the composition of the starting aluminate solution (including $\mathrm{Al}_{2} \mathrm{O}_{3}$ and $\mathrm{Na}_{2} \mathrm{O}$ ); the content of the $\mathrm{Al}_{2} \mathrm{O}_{3}$ in the aluminate solution at the end of the leaching process, which is actually the main target of the modeling procedure. All important process parameters were measured on the daily base, during the year 2011, and these way 330 data lines were collected. The measurements of the parameters were performed only during the regular production mode. During the days in which, from some reasons, process was stopped or interrupted, measurements were not performed.

The bauxite chemical composition was determined using the absorption spectrophotometer Perkin Elmer 4000 and UV/VIS spectrophotometer LAMBDA 15.

The aluminate solutions employed in the leaching process were the regular industrial solutions used in the everyday production process in the alumina factory Birač (Bosnia and Herzegovina). Initial aluminum concentration in the alumina solution was determined by a reverse titration of zinc nitride solution (complexometric titration) with xylenol orange used as the indicator.

The output of the investigated process was the " $\mathrm{Al}_{2} \mathrm{O}_{3}$ leaching recovery" - which will be presented as $\mathrm{Y}$ in the further text - and it refers to the alumina recovery in the digestion process and it has been calculated using the following equation:

$Y_{\left(\mathrm{Al}_{2} \mathrm{O}_{3} \text { leaching recovery }\right)}=\left(1-\frac{\mathrm{Al}_{2} \mathrm{O}_{3}(r . m .) \cdot \mathrm{Fe}_{2} \mathrm{O}_{3}(b)}{\mathrm{Al}_{2} \mathrm{O}_{3}(b) \cdot \mathrm{Fe}_{2} \mathrm{O}_{3}(r . m .)}\right) \cdot 100(\%)$

where:

$\mathrm{Al}_{2} \mathrm{O}_{3(\mathrm{~b})} ; \mathrm{Fe}_{2} \mathrm{O}_{3(\mathrm{~b})}-$ contents in the bauxite (\%) $\mathrm{Al}_{2} \mathrm{O}_{3(\mathrm{r} \mathrm{m})} ; \mathrm{Fe}_{2} \mathrm{O}_{3(\mathrm{r} \mathrm{m})}$ - contents in the residual autoclave mud (red mud) (\%).

According to the material balance of the Bayer process, starting $\mathrm{Al}_{2} \mathrm{O}_{3}$ from the bauxite is divided between the aluminate solution and the residual autoclave mud (red mud). This way, the content of the $\mathrm{Al}_{2} \mathrm{O}_{3}$ in the final aluminate solution, at the end of the leaching process, can be calculated according to the equation (1). By applying the equation (1) for calculating the $\mathrm{Al}_{2} \mathrm{O}_{3}$ degree of recovery during the leaching process, which is based on adopting the "inert" $\mathrm{Fe}_{2} \mathrm{O}_{3}$, it is possible to get the acceptable results (accuracy above 99\%).

The following process parameters were selected as the inputs included in the statistical modeling procedure:

$\mathrm{X}_{1}-\mathrm{Na}_{2} \mathrm{O}$ (caustic) concentration in the starting solution $\left(\mathrm{g} / \mathrm{dm}^{3}\right)$,

$\mathrm{X}_{2}-\mathrm{Al}_{2} \mathrm{O}_{3}$ concentration in the starting solution $\left(\mathrm{g} / \mathrm{dm}^{3}\right)$,

$\mathrm{X}_{3}-\mathrm{Al}_{2} \mathrm{O}_{3}$ content in the bauxite (\%),

$\mathrm{X}_{4}-\mathrm{SiO}_{2}$ content in the bauxite $(\%)$,

$\mathrm{X}_{5}-\mathrm{Fe}_{2} \mathrm{O}_{3}$ content in the bauxite (\%).

During the period when these parameters were measured and the corresponding data base was formed, the operation of the factory was in a stable mode. The boehmite bauxite, used for alumina production, was from the ore body Vlasenica (Bosnia and Herzegovina). The temperature of the leaching process was kept constant at $518 \mathrm{~K}\left(245^{\circ} \mathrm{C}\right)$. The pressure in the autoclave reactors was 35 bar. The size distribution of the bauxite grains was $100 \%-74 \mu \mathrm{m}$, obtained after the hydrocyclone classification. The solid to liquid ratio of the autoclave charge was $\mathrm{S}: \mathrm{L}=1: 5$. Solid phase concentration was 160-200 g/dm ${ }^{3}$, depending on the $\mathrm{Na}_{2} \mathrm{O}$ (caustic) concentration in the returned aluminate solution. The rate of mechanical stirring was $31 \mathrm{~min}^{-1}$.

\section{RESULTS AND DISCUSSION}

For the modeling of the bauxite leaching process, the data were collected by measuring the important input and output process parameters, defined in the previous text.

Because of the different nature and the scope of values of the inputs and the output of the process, all the data lines were standardized and examined for potential outliers before any further modeling procedure. In some cases the strong extreme behavior of the variables was detected (Fig. 1). Those variables were removed from the database. This way, the final database obtained, after the removal of the outliers, contained 299 data lines.

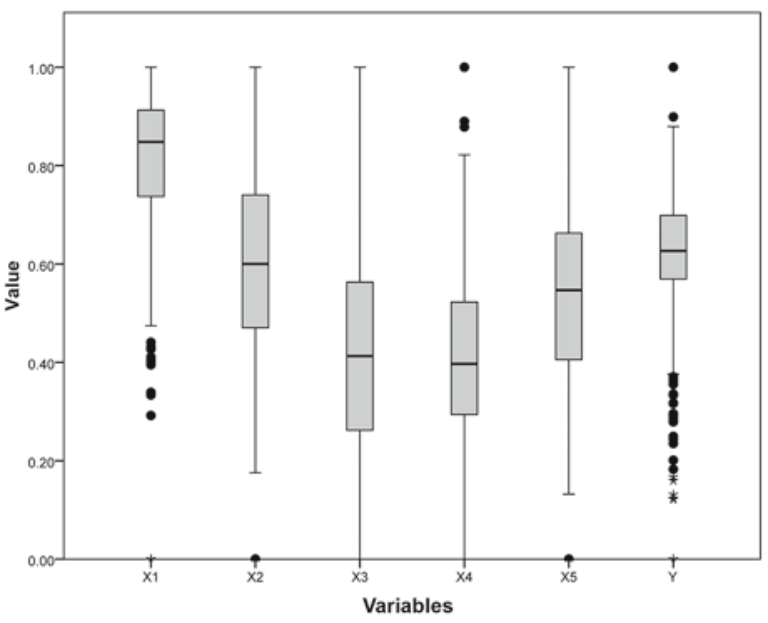

Figure 1. Identifying the outliers of the standardized model variables

The original, non-standardized, values of the measured input parameters of the technological process $\left(X_{1}-X_{5}\right)$ as well as the process quality indicator - output of the process $(\mathrm{Y})$ in the form of descriptive statistics results - are presented in Table 1. The descriptive statistics is presented for the 299 data lines, remaining after the removal of the outliers.

It should be noted that variables $\mathrm{X}_{3}, \mathrm{X}_{4}$ and $\mathrm{X}_{5}$ have a small variance (Table 1). However, these variables are important for the investigated technological process, especially $\mathrm{X}_{3}$. The variable $\mathrm{X}_{3}$ presents the $\mathrm{Al}_{2} \mathrm{O}_{3}$ content in the starting bauxite; it is one of the most important parameters of the Bayer process; thus, it cannot be omitted from the analysis.

\section{ADAPTIVE NETWORK BASED FUZZY INFERENCE SYSTEM}

The reason to use the Adaptive Network Based Fuzzy Inference System (ANFIS) for modeling the boehmite bauxite leaching process, presented in this paper, can be found in the previous research presented in manuscripts $1,15,16$. 
Table 1. Descriptive Statistics of the Input $\left(\mathrm{X}_{\mathrm{i}}\right)$ and the Output (Y) Parameters of the Bauxite Leaching Process Including 299 Data Sets

\begin{tabular}{|l|c|c|c|c|c|c|c|}
\hline \multirow{2}{*}{} & \multirow{2}{*}{ Range } & \multirow{2}{*}{ Minimum } & \multirow{2}{*}{ Maximum } & \multicolumn{2}{|c|}{ Mean } & \multirow{2}{*}{ Std. Deviation } & \multirow{2}{*}{ Variance } \\
\cline { 5 - 6 } & & & & statistic & std. error & & \\
\hline$X_{1}$ & 90.23 & 129.63 & 219.86 & $2.040 \mathrm{E} 2$ & 0.4050 & 10.398 & 108.131 \\
\hline $\mathrm{X}_{2}$ & 48 & 81 & 129 & 109.79 & 0.329 & 8.442 & 71.274 \\
\hline $\mathrm{X}_{3}$ & 4.58 & 50.08 & 54.66 & 51.975 & 0.034 & 0.866 & 0.750 \\
\hline $\mathrm{X}_{4}$ & 3.54 & 4.88 & 8.42 & 6.3208 & 0.022 & 0.562 & 0.316 \\
\hline$X_{5}$ & 4.39 & 22.42 & 26.81 & 24.833 & 0.031 & 0.803 & 0.645 \\
\hline$Y$ & 13.077 & 76.293 & 89.370 & 84.427 & 0.06574 & 1.687 & 2.848 \\
\hline
\end{tabular}

In the paper ${ }^{1}$, attempt was made to develop the numerical model for the calculation of $\mathrm{Al}_{2} \mathrm{O}_{3}$ leaching recovery, based on assembling of differential equations. This type of modeling belongs to the class of the so-called "white box" modeling ${ }^{17,18}$. Although, an accurate enough model was developed, resulting with a predicted accuracy of $98 \%$, it can be stated that the model developing procedure was too complex and resulted in the model equation which cannot be used in production practice, without prior modification. On the other hand, bauxite leaching process was also the target of linear statistics modeling (MLRA), presented in the manuscript ${ }^{15}$, and the nonlinear statistic modeling based on artificial neural networks (ANNs) in ${ }^{\mathbf{1 6}}$. Both of those approaches belong to the so-called class of "black box" modeling ${ }^{19,20}$. The MLRA approach resulted with low accuracy of obtained model $\left(\mathrm{R}^{2}=0.56\right)$, while the ANNs approach resulted with higher accuracy $\left(\mathrm{R}^{2}=0.723\right)$. However, the demerit of the ANNs based model, developed in the SPSS softwa$\mathrm{re}^{21}$ (PASW Statistics) lies in the fact that it is based on only one rule describing the behaviour of input variables. In this way it is difficult to use the same model on the validation of a new set of input parameters, obtained from the same process in subsequent time intervals ${ }^{22}$.

Owing to this reason, it was decided to develop the ANFIS based numerical model, which is based on more than one rule describing the behaviour of input variables. Considering that the ANFIS procedure can allocate the values of each input variable in more than one scale, it can be used for modelling the set of input variables with a wide range; such are the variables $\mathrm{X}_{1}, \mathrm{X}_{2}$ and $\mathrm{Y}$, in Table 1. Examples of an application of ANFIS procedure in modelling different complex technological processes are presented in many contemporary references ${ }^{23,24,25}$.

The ANFIS system serves as a basis for constructing a set of fuzzy if-then rules with appropriate membership functions to generate the stipulate input-output pairs. The ANFIS structure is obtained by embedding the fuzzy interference system into the framework of adaptive networks. An adaptive network is a network structure consisting of a number of nodes connected through directional links. The outputs of these adaptive nodes depend on modifiable parameters pertaining to these nodes. The learning rule specifies how these parameters should be varied through iterations to minimize the final error. On the other hand, according to Takagi and Sugeno ${ }^{\mathbf{2 6}}$ the fuzzy inference system (FIS) is a framework based on fuzzy set theory and fuzzy if-then rules. Three main components of a FIS structure are: a rule base, a database, and a reasoning mechanism. The rule base has an adequate number of if-then rules for the levels of ranges of input variables. For example, one rule might be "if the $\mathrm{SiO}_{2}$ content in the starting sample is low, than the degree of $\mathrm{Al}_{2} \mathrm{O}_{3}$ recovery is high", where low and high are linguistic variables. The database defines the membership functions applied in fuzzy rules and the reasoning mechanism performs the inference procedure ${ }^{27,28}$.

This way, for example that there are two input variables $\left(\mathrm{X}_{1}\right.$ and $\left.\mathrm{X}_{2}\right)$, and assuming that their ranges can be divided in two levels, there would be the rule base with two rules for modeling the value of output variable $\mathrm{Y}$ :

Rule 1: If $\mathrm{X}_{1}$ is in the range $\mathrm{A}_{1}$ and $\mathrm{X}_{2}$ is in the range $\mathrm{B}_{1}$, then $\mathrm{f}_{1}=\mathrm{p}_{1} \mathrm{x}_{1}+\mathrm{q}_{1} \mathrm{x}_{2}+\mathrm{r}_{1}$

Rule 2: If $\mathrm{X}_{1}$ is in the range $\mathrm{A}_{2}$ and $\mathrm{X}_{2}$ is in the range $\mathrm{B}_{2}$, then $\mathrm{f}_{2}=\mathrm{p}_{2} \mathrm{x}_{1}+\mathrm{q}_{2} \mathrm{x}_{2}+\mathrm{r}_{2}$

In the case $\mathrm{f}\left(\mathrm{x}_{1}, \mathrm{x}_{2}\right)$ is a first-order polynomial, then the model is called a first-order Sugeno fuzzy model ${ }^{26}$.

The graphical presentation of general ANFIS network is presented in Figure 2.

As can be seen in Figure 2, ANFIS architecture can be presented with five layers. Where $\mathrm{X}_{1}$ and $\mathrm{X}_{2}$ are inputs to nodes in layer $1, \mathrm{~A}_{\mathrm{i}}$ and $\mathrm{B}_{\mathrm{i}}$ are the linguistic label of the ranges of input variables (small, large, etc), associated with the node function. Membership functions of nodes located in layer $1\left(\mathrm{O}_{\mathrm{i}}{ }^{1}=\mathrm{mA}_{\mathrm{i}}\left(\mathrm{X}_{\mathrm{i}}\right)\right.$ or $\left.\mathrm{O}_{\mathrm{i}}{ }^{2}=\mathrm{mB}_{\mathrm{i}}\left(\mathrm{X}_{\mathrm{i}}\right)\right)$ specifies the degree to which the given $X_{i}$ satisfies the quantifier $A_{i}, B_{i}$, etc. Usually, membership functions are either bell-shaped with maximum equal to 1 and minimum equal to 0 , or Gaussian function.

Nodes located in the layer 2 are multipliers, which are multiplying the signals exiting the layer 1 nodes. For example $\mathrm{O}_{\mathrm{i}}^{2}=\mathrm{W}_{\mathrm{i}}=\mathrm{mA}_{\mathrm{i}}\left(\mathrm{X}_{\mathrm{i}}\right) \times \mathrm{mB}_{\mathrm{i}}\left(\mathrm{X}_{\mathrm{i}}\right), i=1$, 2 , etc. Output of each node is representing the firing strength of a rule. The $i$-th node of layer 3 calculates the ratio of $i$-th rules firing strength to sum of all rules firing strengths.

This way $\mathrm{O}_{\mathrm{i}}{ }^{3}=\overline{W_{i}}=\mathrm{W}_{\mathrm{i}} /\left(\mathrm{W}_{1}+\mathrm{W}_{2}+\ldots\right), i=1$, $2, \ldots$ Every node $i$ in the layer 4 has a node function of following type: $\mathrm{O}_{\mathrm{i}}^{4}=\overline{W_{i}} \cdot \mathrm{f}_{1}=\overline{W_{i}} \cdot\left(\mathrm{p}_{\mathrm{i}} \mathrm{x}_{1}+\mathrm{q}_{\mathrm{i}} \mathrm{x}_{2}+\right.$ $r_{i}$ ), where $p_{i}, q_{i}$ and $r_{i}$ will be referred to as consequent parameters. The single node of layer 5 is the node that computes the overall output as the summation of all incoming signals i.e., $\mathrm{O}_{\mathrm{i}}^{5}=\sum_{i} \overline{W_{i} f_{i}}=\frac{\sum_{i} W_{i} f_{i}}{\sum_{i} W_{i}}$

Training of the parameters in the ANFIS structure is accommodated according to the hybrid learning rule algorithm which is the integration of the gradient descent method and the least square methods. In the forward pass of the algorithm, functional signals go forward until 

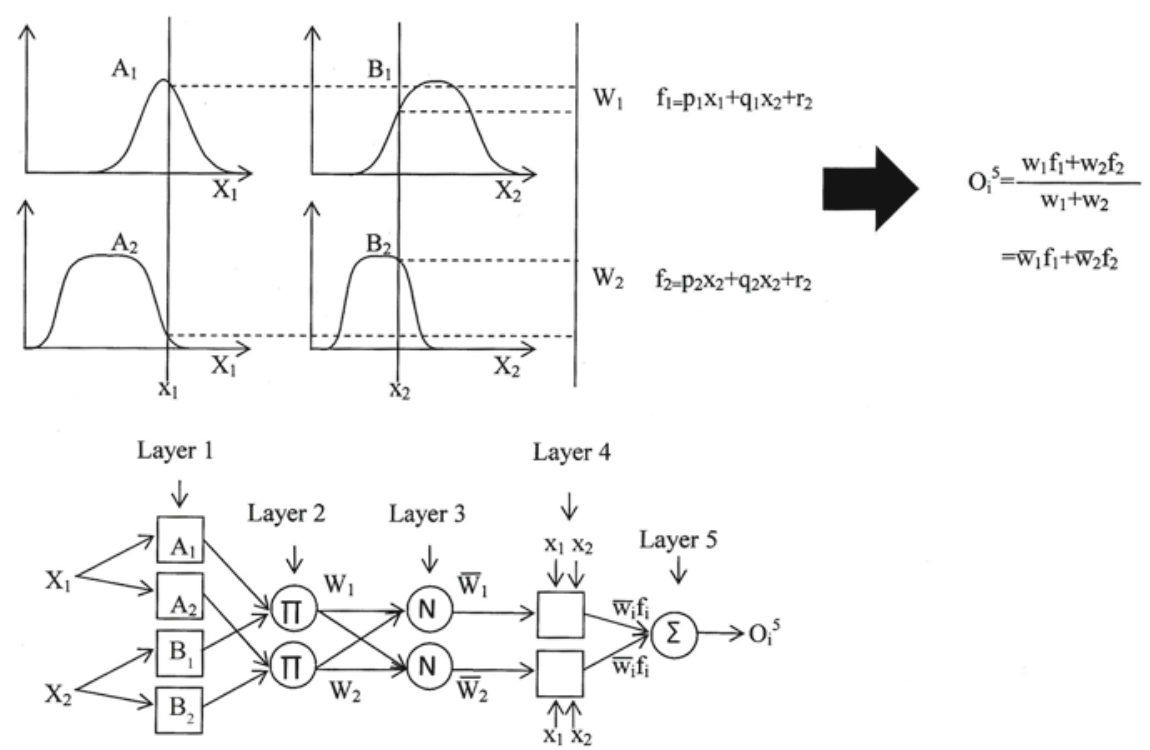

Figure 2. Graphical presentation of ANFIS architecture

layer 4 and the consequent parameters are identified by the least squares method to minimize the measured error. In the back propagation pass, the premise parameters are updated by the gradient descent method ${ }^{27}$.

To apply the ANFIS methodology, to the bauxite leaching process presented in this paper, the assembly of 299 input and output samples was divided into two groups. The first group consisted of 214 (»70\%) at random selected samples, and it was used for training of the model, whereas the second group consisted of 85 (»30\%) remaining samples from the starting data set, and it was used for testing the model. The selection of the variables for these two stages was performed by using the random number generator. The random number generator, which was used, is based on Bernoulli distribution.
In the gathering data process for the training and the testing stage, the values for each input and the output variable were standardized by the maximum values. This was done because of different nature and measuring units of the input and the output variables.

According to the trends and the ranges of the time series for the input variables, presented in Table 1, it was decided that two rules ANFIS network should be applied. Selected membership function was Gaussian one. Representation of the membership functions for all 5 input variables is presented in Figure 3.

During the training phase the correction of the weighted parameters $\left(\mathrm{p}_{\mathrm{i}}, \mathrm{q}_{\mathrm{i}}, \mathrm{r}_{\mathrm{i}}\right.$, etc $)$ of the connections, presented in the Figure 2, is achieved through the necessary number of iterations, until the mean squared error
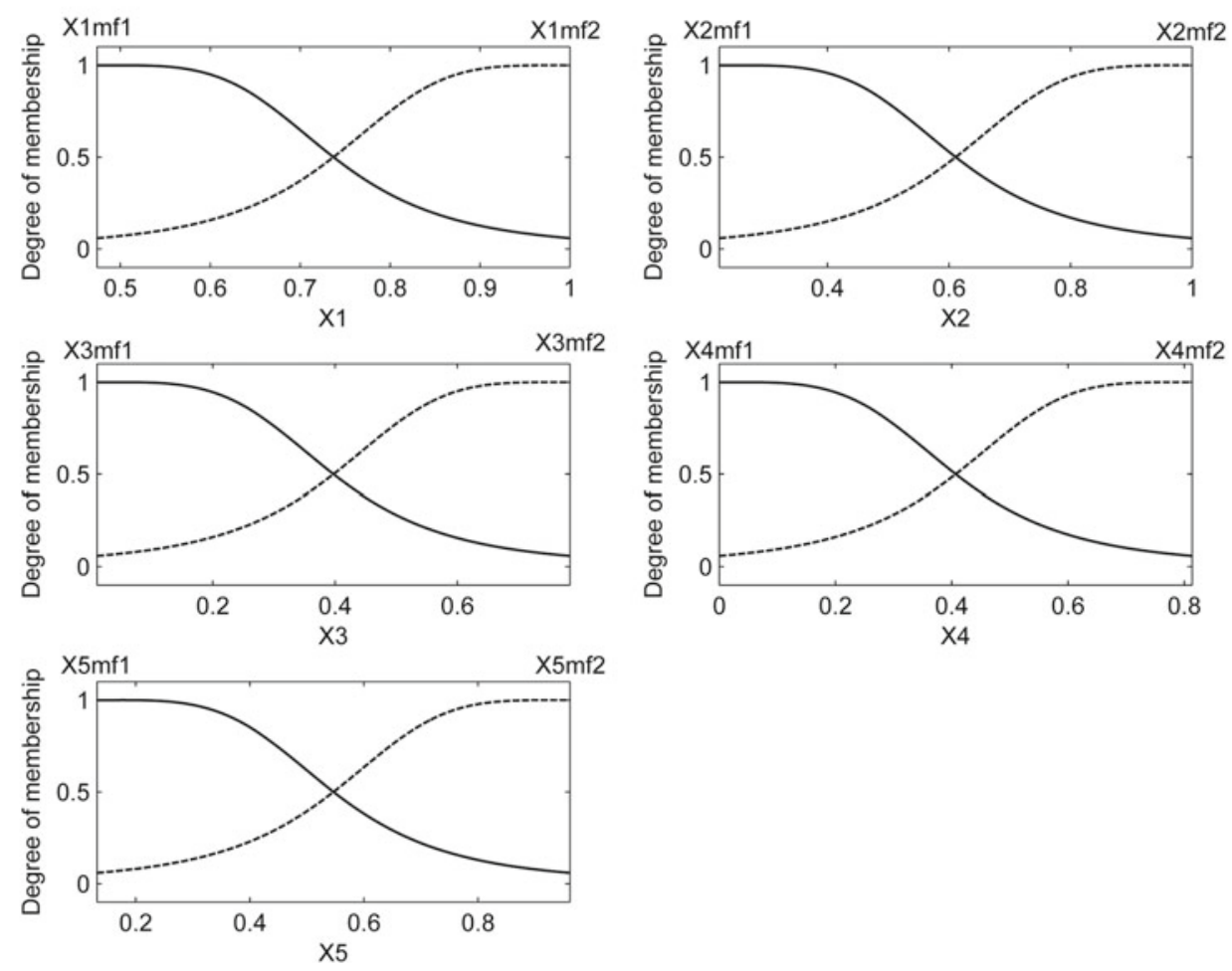

Figure 3. Membership functions of input variables $\left(X_{1}\right.$ to $\left.X_{5}\right)$ 
between the calculated and measured outputs of the ANFIS network, is minimal. During the second phase, the remaining $30 \%$ of the data is used for testing the "trained" network. In this phase, the network uses the weighted parameters determined during the first phase. These new data, excluded during the network training stage, are now incorporated as the new input values $\left(\mathrm{X}_{\mathrm{i}}\right)$ which are then transformed into the new outputs (Y). For the calculation presented in this paper MATLAB ANFIS editor was used ${ }^{29}$.

In the phase of the network training, the necessary number of iterations was performed until the error (RMSE) between the measured output of the $\mathrm{Al}_{2} \mathrm{O}_{3}$ leaching recovery - $\mathrm{Y}$ and the calculated values wasn't minimized and remained constant. In the case of the investigation presented in this paper, the optimal number of iterations (epochs) was 10.

In the testing phase, the remaining data lines were used to test the trained ANFIS network. Figure 4, presents the obtained values of the Root Mean Squared Error (RMSE), for all ten epochs, during the training and the testing stage. The obtained results from the training and the testing stage can be evaluated by comparison of the calculated values $Y$ with the measured ones. Comparison between the measured and the ANFIS model predicted values of the $\mathrm{Al}_{2} \mathrm{O}_{3}$ leaching recovery $(\mathrm{Y})$ during training stage, are presented in Figure 5.

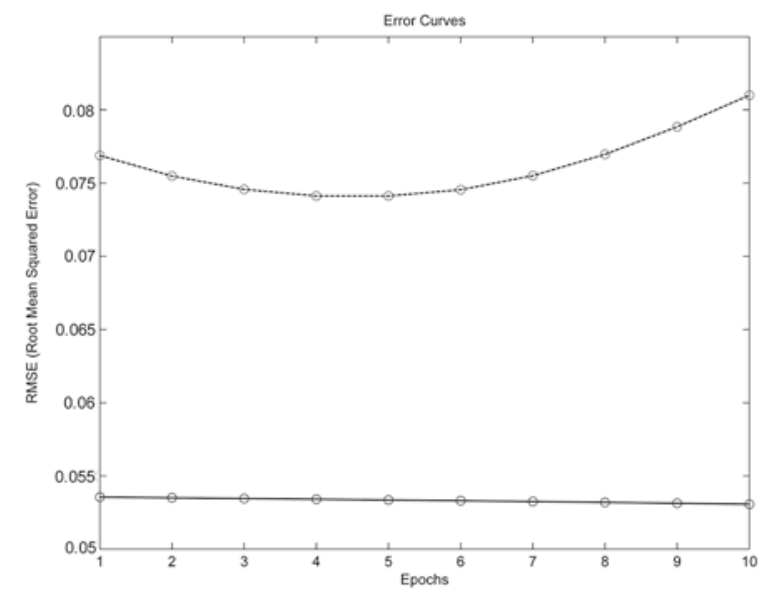

Figure 4. RMSE of the ANFIS model during training ( - ) And the testing stage (---)

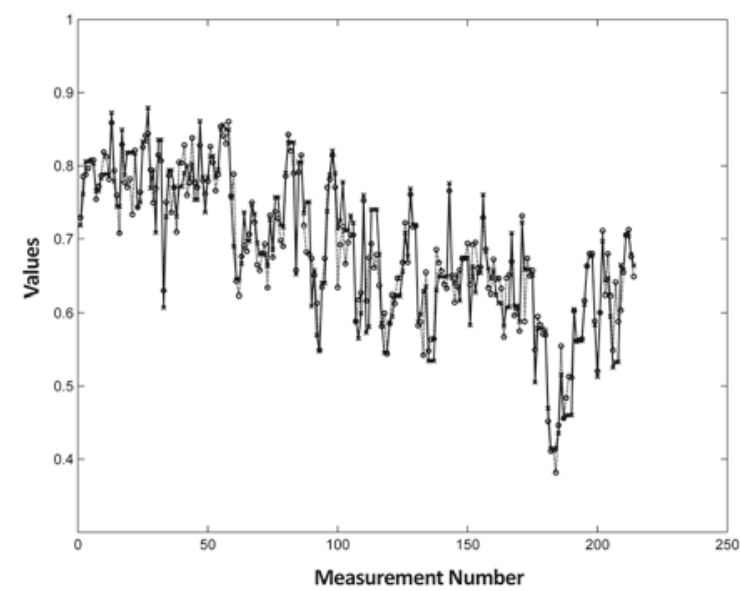

Figure 5. Time series of measured $(-\mathrm{x}-)$ and ANFIS model predicted (--O--) values of the $\mathrm{Al}_{2} \mathrm{O}_{3}$ recovery in the training stage
The final fidelity of the obtained ANFIS model can be assessed by the coefficient of determination $\left(\mathrm{R}^{2}\right)$ between the measured and the model predicted values of the $\mathrm{Al}_{2} \mathrm{O}_{3}$ leaching recovery $(\mathrm{Y})$, in the training and the testing stage. The $\mathrm{R}^{2}$ values are presented in Figure $6 \mathrm{a}$ and $6 \mathrm{~b}$, for the training and the testing stage, respectively.
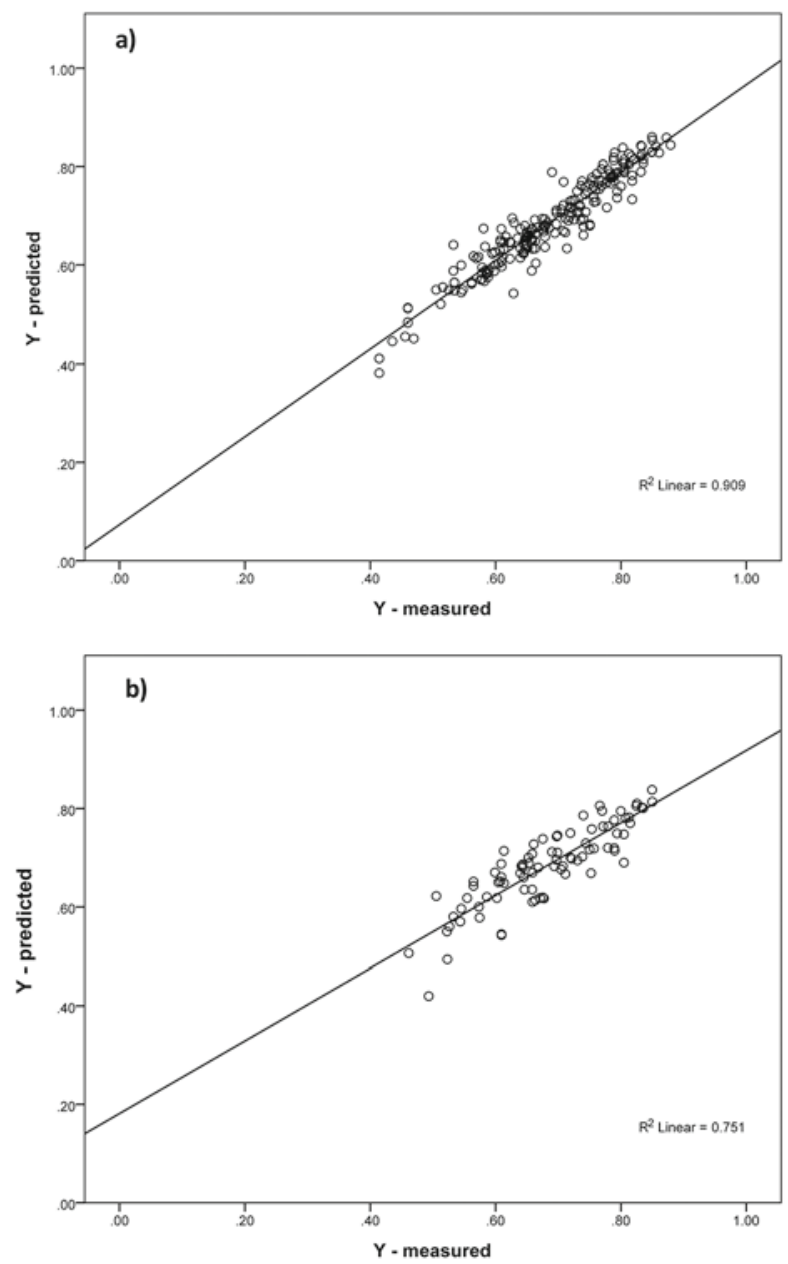

Figure 6. The recovery predicted by ANFIS vs. the actual measured $\mathrm{Al}_{2} \mathrm{O}_{3}$ recovery in the (a) training and (b) testing stage

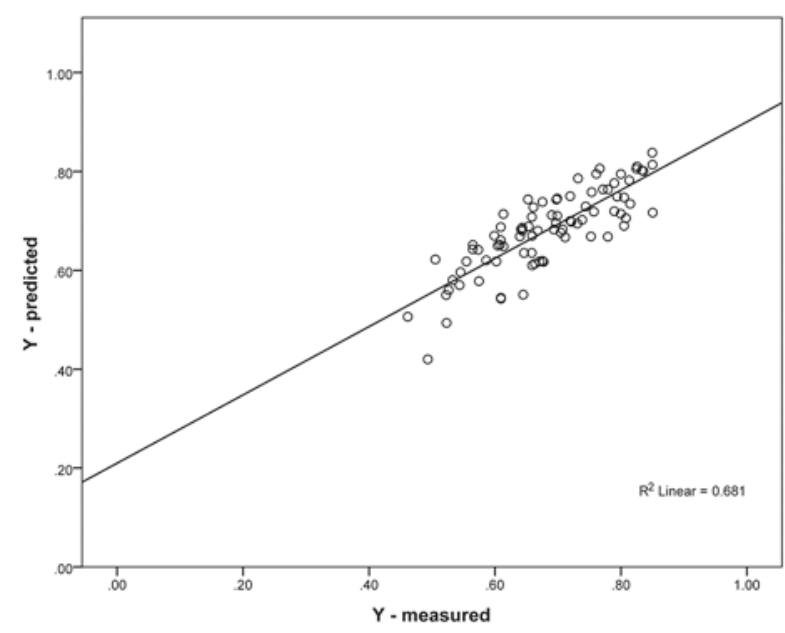

Figure 7. The recovery predicted by ANFIS vs. the actual measured $\mathrm{Al}_{2} \mathrm{O}_{3}$ recovery in the validation stage 
The ANFIS modelling approach, predicted the $\mathrm{Al}_{2} \mathrm{O}_{3}$ leaching recovery with a determination coefficient $R^{2}=$ 0.909 (Fig. 6a) and $R^{2}=0.751$ (Fig. 6b), in the training stage and the testing stage - respectively, which represents very large significance. This means that the $\mathrm{Al}_{2} \mathrm{O}_{3}$ leaching recovery can be predicted with the accuracy above $75 \%$, based on the known input parameters $\left(\mathrm{X}_{1}\right.$ to $\mathrm{X}_{5}$ ), using the ANFIS model described in this paper.

To further sustain the applicability of the proposed ANFIS model, validation vas performed with the data collected during the year 2012. For that purpose, an additional set of 85 data lines was recorded at the same production line, during the period January-March 2012. This was the same number of data, as previously used in the testing stage. With this new data base, validation of the model was performed. The ANFIS model responded with expected high accuracy, resulting with the coefficient of determination $\mathrm{R}^{2}=0.681$ (Fig. 7).

\section{CONCLUSIONS}

Values of the correlation analysis of the degree of $\mathrm{Al}_{2} \mathrm{O}_{3}$ recovery from the boehmitic bauxite leaching under industrial conditions in the factory Birač, Zvornik (Bosnia and Herzegovina) were determined using the ANFIS methodology. The selected ANFIS structure consisted of 214 (70 pct) samples for training and 85 (30 pct) for testing.

The values of the coefficient of determination $\left(\mathrm{R}^{2}\right)$ were 0.909 and 0.751 , in the training and the testing stage - respectively. These results indicated a highly acceptable degree of fitting of the dependence $\mathrm{Y}=$ $\mathrm{f}\left(\mathrm{X}_{1}-\mathrm{X}_{5}\right)$, obtained using MLRA procedure as part of the Math Lab software application, version 7.1 (2007).

Further validation of the developed model was performed with additional data base containing 85 new data lines, obtained in subsequent measurements. As expected, the model responded with adequately high accuracy resulting in $\mathrm{R}^{2}=0.681$, for the validation data set. This value indicated that the defined elements of the ANFIS structure can be applied to different conditions in the same factory, as well as generally to conditions in any factory that uses the Bayer technology for alumina production.

\section{ACKNOWLEDGEMENT}

The authors also feel indebted to Mr. R. Smiljanić, the manager of production in the Alumina factory Birač A.D., Zvornik (Bosnia and Herzegovina), who enabled the collection of the industrial data used in this article.

\section{LITERATURE CITED}

1. Đurić, I., Mihajlović, I. \& Živković, Ž. (2010). Kinetic Modelling of Different Bauxite Types in the Bayer Leaching Process. Can. Metall. Q. 49(3), 209-218. DOI: 10.1179/00084 4310795937730.

2. Gontijo, G.S., Brandao de Araujo, A.C., Prasad, S., Vasconcelos, L.G.S., Alves, J.J.N. \& Brito, R.P. (2009). Improving the Bayer process productivity - An industrial case study. Min. Eng. 22, 1130-1136. DOI: 10.1016/j.mineng.2009.04.010.

3. Habashi, F. (1997). Handbook of Extractive Metallurgy. Hoboken, New Jersey, NY, USA: John Wiley \& Sons, Inc.
4. Habashi, F. (2009). Recent trends in extractive metallurgy. J. Mining Metall. 45 B(1), 1-13. DOI: 10.2298/JMMB0901001H.

5. Zhang, Y.F., Li, Y.H. \& Zhang, Y. (2003). Phase diagram for the system $\mathrm{Na}_{2} \mathrm{O}-\mathrm{Al}_{2} \mathrm{O}_{3}-\mathrm{H}_{2} \mathrm{O}$ at high alkali concentration. $J$. of Chem. \& Eng. Data. 48(3), 617-620. DOI: 10.1021/je025611g.

6. Whittington, B.I., Fletcher, B.L. \& Talbot, C. (1998). The effect of reaction conditions on the composition of desilication product (DSP) formed under simulated Bayer conditions. Hydrometall. 49, 1-22. DOI: 10.1016/S0304-386X(98)00021-8.

7. Jamialahmadi, M. \& Muller-Steinhagen, H. (1998). Determining silica solubility in Bayer process liquor. JOM. 50(11), 44-49. DOI: 10.1007/s11837-998-0286-6.

8. Palmer, D.A., Benezeth, P., Weselowski, D.J. \& Helc, S. (2003). Experimental study of the dissolution of aluminum phases as a function of temperature, caustic concentration and additives. In Light Metals Symposium. 15-17 November 2001 (pp. 5-10), Warrendale, Pennsylvania. USA, The Minerals, Metals \& Materials Society.

9. Xu, B., Wingate, C. \& Smith, P. (2009). The effect of surface area on the modelling of quartz dissolution under conditions relevant to the Bayer process. Hydrometall. 98, 108-115. DOI:10.1016/j.hydromet.2009.04.006.

10. Chelgani, S.C. \& Jorjani, E. (2009). Artificial neural network prediction of $\mathrm{Al}_{2} \mathrm{O}_{3}$ leaching recovery in the Bayer process - Jajarm alumina plant (Iran). Hydrometall. 97, 105-110. DOI:10.1016/j.hydromet.2009.01.008.

11. Songqing, G., Zhonling, Y. \& Lijuan, Q. (2002). Investing method of Bayer digestion process of diasporic bauxite in China. In Light Metals Symposium. 17-21 February 2002 (pp. 83-88), Warrendale, Pennsylvania. USA, The Minerals, Metals \& Materials Society.

12. Pereira, J.A.M., Schwaab, M., Dell'Oro, E., Pinto, J.C., Monteiro, J.L.F. \& Henriques, C.A. (2009). The kinetics of gibbsite dissolution in $\mathrm{NaOH}$. Hydrometall. 96, 6-13. DOI: 10.1016/j.hydromet.2008.07.009.

13. Panias, D., Asimidis, P. \& Paspaliaris, I. (2001). Solubility of boehmite in concentrated sodium hydroxide solutions. Model development and assessment. Hydrometall. 59, 15-29. DOI: 10.1016/S0304-386X(00)00146-8.

14. Cao, S., Zhang, Y.F. \& Zhang, Y. (2009). Preparation of sodium aluminate from the leach liquor of diaspoiric bauxite in concentration $\mathrm{NaOH}$ solution. Hydrometall. 98, 298-303. DOI:10.1016/j.hydromet.2009.05.016.

15. Đurić, I., Đorđević, P., Mihajlović, I., Nikolić, Đ. \& Živković, $\breve{Z}$. (2010). Prediction of $\mathrm{Al}_{2} \mathrm{O}_{3}$ leaching recovery in the Bayer process using statistical multilinear regression analysis. $J$. Mining Metall. 46(2) B 161-169. DOI:10.2298/JMMB1002161D.

16. Đurić, I., Mihajlović, I., Živković \& Kešelj, D. (2011). Artificial neural network prediction of aluminum extraction from bauxite in the Bayer process. J. Serb. Chem. Soc. 76(9) 1259-1271. DOI: 10.2298/JSC110526193D.

17. Wernick, P. \& Lehman, M.M. (1999). Software process white box modelling for FEAST/1. J. Syst. Software.46, 193-201. DOI: 10.1016/S0164-1212(99)00012-6.

18. Davoody, M., Zahedi, G., Biglari, M., Meireles, M.A.A. \& Bahadori, A. (2012). Expert and gray box modeling of high pressure liquid carbon dioxide extraction of Pimpinella anisum L. seed. J. Supercritical Fluids. 72, 213-222. DOI: 10.1016/j. supflu.2012.09.002.

19. Mjalli, F.S., Al-Asheh, S. \& Alfadala, H.E. (2007). Use of artificial neural network black-box modeling for the prediction of wastewater treatment plants performance. J. Environ. Manage. 83, 329-338. DOI: 10.1016/j.jenvman.2006.03.004.

20. Prada, L., Garcia, J., Calderon, A., Garcia, J.D. \& Carretero, J. (2013). A novel black-box simulation model methodology for predicting performance and energy consumption in commodity storage devices. Simul. Model. Pract. Th. 34, 48-63. DOI: 10.1016/j.simpat.2013.01.006.

21. PASW Statistics, V.18, Formerly called SPSS Statistics, SPSS Inc. 
22. Mihajlović, I. Štrbac, N., Đorđević, P., Ivanović, A. \& Živković, Ž. (2011). Technological process modeling aiming to improve its operations management. Serb. J. Manag. 6 (2), 135-144. DOI: 10.5937/sjm1102135M.

23. Yetilmezsoy, K., Fingas, M. \& Fieldhouse, B. (2011). An adaptive neuro-fuzzy approach for modeling of water-in-oil emulsion formation. Colloid. Surface. A. 389(1-3), 50-62. DOI: 10.1016/j.colsurfa.2011.08.051.

24. Canete, J.F., Garcia-Cerezo, A., Garcia-Moral, I., Del Saz, P. \& Ochoa, E. (2013). Object-oriented approach applied to ANFIS modeling and control of a destillation column. Expert Syst. Appl. 40(14), 5648-5660. DOI: 10.1016/j.eswa.2013.04.012.

25. Chauhan, S., Singh, M. \& Meena, V.K. (2013). Comparative study of BOF steelmaking process based on ANFIS and GRNN model. IJEIT. 2(9), 198-202. Retrieved November 15, 2013, from http://ijeit.com/vol\%202/Issue\%209/IJEIT1412201303_36.pdf

26. Takagi, T. \& Sugeno, M. (1985). Fuzzy identification of systems and its application to modeling and control. IEEE Trans. Systems. Man. Cybernetics. 15(1), 116-132. DOI: 00189472/85/0100-0116\$01.00.

27. Jang, M., Cai, L., Udeani, G., Slowing, K., Thomas, K., Beecher, C., Fong, H., Farnsworth, N., Kinghorn, A.D., Mehta, R., Moon, R. \& Pezzuto, J. (1997). Cancer Chemopreventive Activity of Resveratrol, a Natural Product Derived from Grapes. Sci. Magazine. 275, 218-220. DOI: 10.1126/science.275.5297.218.

28. Savić, M., Mihajlović, I. \& Živković, Ž. (2013). An ANFIS - Based Air Quality Model for Prediction of $\mathrm{SO}_{2}$ Concentration in Urban Area. Serb. J. Manag. 8(1), 25-38. DOI: $10.5937 / \mathrm{sjm} 8-3295$.

29. MATLAB, V.7.1, The MathWorks Inc., Natick, MA, 2007. 